\title{
Relationships among Risk Assessment, Risk Perception and Acceptance Model of the Residents near Nuclear Power Plants in Japan
}

\author{
Yuichi Otsuka \\ Department of System safety, Nagaoka University of Technology, Nagaoka, Japan \\ Email: otsuka@vos.nagaokaut.ac.jp
}

Received 6 April 2015; accepted 2 June 2015; published 4 June 2015

Copyright (C) 2015 by author and Scientific Research Publishing Inc. This work is licensed under the Creative Commons Attribution International License (CC BY). http://creativecommons.org/licenses/by/4.0/

(c) (i) Open Access

\section{Abstract}

This study aims at revealing the relationships among risk assessment result, risk perception model and risk acceptance model of the residents near nuclear power plants in Japan. Risk acceptance model is based on the trust of resident to nuclear power plants (NPPs) companies. The risk perception of the residents is very fragile and is not always based on objective technical knowledge. In addition, there are two models of risk acceptance: traditional trust model and salient value similarity model. In order to discuss the risk communication framework between NPPs with residents, applicability of two modes on the perception of the residents should be investigated. The author collected questionnaire from local resident near Kashiwazaki-Kariwa NPP in Niigata, Japan. Severity of risk is significantly affected by the extents of risks, not by amount of knowledge. Radiation relating hazard is normally evaluated higher risk. Risk acceptance level is significantly related to the factors of social benefits and trust to the NPPs company, not by regional interest nor amount of knowledge. Furthermore, value similarity model was not significant in this study. The results demonstrated that risk acceptance model of local residents near NPPs could be arranged by traditional trust model. In order to establish mutual trustworthy relationships between local residents and NPPs engineer, expert knowledge in nuclear power, communication skills, and expertise in safety are necessary to the engineers.

\section{Keywords}

Risk Assessment, Risk Perception, Risk Communication, Risk Acceptance Model 


\section{Introduction}

The Niigata Chuetsu-oki earthquake that occurred on July 16, 2007 caused severe damage to the KashiwazakiKariwa region around the city of Kashiwazaki. Significantly, the Kashiwazaki-Kariwa nuclear power plant, whose capacity is the largest in the world, was affected. Images of black smoke rising from the power plant shocked local communities. The specific damage to the power plant concerned fire in the transformers, damage to buildings and equipment from the seismic activity, and traces of radiation leakage. Under these circumstances, it has not been possible to dispel the concerns and anxieties of the local population and resume the power plant's operation. The main reason for this is the difference between the perceptions of the technical expert and the citizens about the risks that nuclear power plants represent.

In the Special Measures Concerning Nuclear Emergencies, a nuclear disaster has been defined as "a situation in which radioactive material or radiations at an abnormal level has been released outside the nuclear site" [1]. Nuclear disasters are then synonymous with disasters due to radiation. However, this definition of nuclear disasters is not necessarily the same definition that local residents might have regarded "the risk of a nuclear power plant”. The report by Niigata Prefecture about the damage caused by the Chuetsu-oki earthquake pointed out that the engineers at the nuclear power plant stated there was no need for an immediate response to the black smoke because the fire in the transformers was not a danger to the reactor. On the contrary the local residents were reportedly filled with anxiety because they did not understand the relationship of the smoke to the safety of the reactor. This difference in the perceptions of the risk influences the public's acceptance of nuclear power plants (NPPs). Local residents are skeptical about the extent to which crisis response measures have been made for the management of potentially fatal equipment. This attitude would obviously prejudice the public's acceptance of nuclear power plants. The difference in the perceptions of risk is not due to differences in technical knowledge, but the fact that risk assessment information is not shared between the technical experts and the public. For example, even if the mechanism of a hazardous event were not known, if the probability of an occurrence was foreseen and the countermeasures against it were common knowledge, the extent of anxiety by risk phenomena would likely be reduced. Understanding to share risk assessment information can build mutual confidence between engineers and the public.

The anxiety in the local residents caused by differences between the engineers' and the residents' perceptions of the risk posed by the nuclear power plant is an important issue in the Kashiwazaki-Kariwa region. Public anxiety casts a shadow over the ability to maintain the region's acceptance of nuclear power plants. Hence, it is necessary to clarify the ways that knowledge of the factors related to radiation and other factors as sources of risk affect public acceptance and trust of nuclear power plants. There are two models of risk acceptance: traditional trust model and salient value similarity model [2]-[4]. In order to discuss the risk communication framework between NPPs and residents, practical adaptively of the two models on local residents are indispensable. Therefore, this study aims at revealing the relationships among risk assessment result, risk perception model and risk acceptance model of the residents near nuclear power plants. The factors that determine acceptance examined in this study are risk perception, benefit recognition, and source of risk. Data were derived from responses to an Internet-based and mail questionnaire survey of the residents of the Kashiwazaki-Kariwa region. Based on the results of the survey, the study describes the role that the local residents want engineers to fill regarding risk assessment with respect to assessing the acceptability of nuclear power plants.

\section{Investigation Method}

\subsection{Selection of Respondents for the Survey}

A sample of 500 residents of Kashiwazaki City and Kariwa in Niigata Prefecture that were older than 20 years old was selected. The number of respondents from each city was first determined based on the population ratio and each municipality was classified according to gender and age. 476 subjects were then selected from Kashiwazaki (235 men and 241 women) as potential respondents for the survey and 24 were selected from Kariwa (12 men and 12 women). The electoral rolls of the municipalities were used to sample the names and addresses of the respondents. The respondents' names, genders, ages (to identify age groups) and addresses were extracted from the first print edition of the electoral roll by pre-determined random intervals.

\subsection{Implementation of the Questionnaire}

The questionnaire was sent by mail from February 22th to March 15th, 2010 with soliciting the cooperation of 
the respondents. The questionnaire could be completed either on the Internet or returned by mail, according to the choice of the respondent. Moreover, with respect to Internet responses, a function that recorded the input IP address was able to prevent the problems of duplicate posts. Furthermore, there was a function that prevented multiple submissions from the same personal computer, which meant that the Internet-based responses could be regarded as close to equivalent to the questionnaires received by mail.

\subsection{Contents of the Questionnaire}

Questions that were related to the acceptability, risk scenario by nuclear power plants, benefits to the local community, individual benefits, feelings of trust in power generation companies, and the extent of value similarity between the values of power producers and the respondents' values were included in the questionnaire. The details of the questions are shown as the follows.

1) Risk perception

Because hazards are associated with radiation, questions related to core meltdown, radiation leakage and the release of radioactive water were asked. Questions about failure of machinery and piping equipment and fire on the site were provided as examples of other hazards. For each hazard, the respondents were asked to evaluate three factors. The rating scale was excerpted from the international standard ISO14120 (JIS B9700) on machine safety [5].

a) The probability of the occurrence of risk ( 1 = no possibility through $5=$ occurring frequently);

b) The extent of damage caused by risk ( 1 = negligible damage through 4 = fatal damage $)$;

c) The severity of risk (1 = acceptable through 4 = unacceptable);

2) Benefits of power plants

Six things were listed as benefits to society and the respondents' region. For each question, the respondents were asked to select one of five options, where $1=I$ do not agree with through $5=$ I agree with

3) Trust in power plants

Seven questions were asked about the extent of trust in the company's intentions and abilities. For each question, the respondents were asked to select one of five options, where $1=I$ do not agree with through $5=$ I agree with. The above two types of questions were modifications of questions used by Kimura et al. (2003) [6].

4) Awareness of the values of the company

Five questions were asked about the benefits and the extent of commonality between the company and the respondents regarding values related to trust. For each question, one of five options was requested, $1=I$ do not agree with through 5 = I agree with.

5) Requirements of engineers

There were 16 questions about the things that the respondents believed were necessary to enable engineers to understand the advantages and disadvantages of nuclear power plants. The questions consisted of proficiency in nuclear energy and safety, engineers' regional affinity, communication skills, and a sense of belonging to the organization. For each question, one of five options was requested, where $1=I$ do not agree with through $5=I$ agree with. These questions were selected by referring to Yagi et al. (2007) [7] and from the results of a preliminary survey.

6) Face sheet

Each respondent reported gender and age.

7) Other

A consent column was provided in which the respondents indicated that they understood the purpose of the survey and agreed to the results being used for academic and research purposes.

8) Amount of knowledge

To ascertain the objective knowledge of the respondents regarding nuclear power plants, there were eight questions to which the respondents answered by marking $\mathrm{X}$ or O. Examples of the questions are: 1.There are 7 units in Kashiwazaki Kariwa NPP (Answer: O); 2. Reactor type of Kashiwazaki Kariwa NPP is pressurized water reactor (PWR) (Answer: $\mathrm{X}$ )

\section{Results and Discussion}

\subsection{Attributes of the Respondents}

The total number of responses received by Internet and mail was 249 (response rate: 49.8\%). Excluding the cas- 
es with item nonresponse, multiple answers to one question, and those that did not agree to the use of the results for academic and research purposes, the total number of respondents for use in the analysis was 208 (proportion of valid responses: $41.6 \%$ ). Because the response rate of other similar studies is about $40 \%$ [6], an equivalent elicitation was accomplished by this survey.

The response rate by age distribution of the valid respondents is shown in Table 1 . The response rate was relatively small among the respondents in their 20s or 30s in the age distribution. The numbers of persons in these two groups are smaller compared to the number of respondents in their 50s. Consequently, the response rates of those in their 20s and those older than age of 70 were lower than the average. The male to female ratio was approximately 1:1.

\subsection{Response Situation with Respect to Risk Perception}

Figure 1 shows the respondents' perceptions of risk regarding the five types of hazards. The vertical axis shows the average extent of damage and the horizontal axis indicates the average probability of occurrence. Both factors were unacceptable to the respondents when the values were large.

Each point circle in Figure 1 shows the extent of unacceptability of the risk. The correspondence between the point scale and the extents of unacceptability were: 2 = acceptable with countermeasures, $3=$ undesirable, and $4=$ not acceptable. First, there was a vast difference in the respondents' perceptions of the extent of damage depending on whether or not the hazard involved radiation leakage. Furthermore, the extent of the damage due to fire or failure of equipment or piping was perceived as relatively smaller than when there was radiation leakage. The fact that risk perceptions have a negative image indicates that the respondents determine the extents by combining the extent of damage with the probability of its occurrence. In short, risk perceptions of the resident are total based on rational basis.

\subsection{Relationship between Amount of Knowledge and Risk Perception}

The results of the multiple regression analysis performed on the relationship between risk perceptions and the amount of knowledge where the magnitude of the risk was the dependent variable and the frequency of occurrence of risk, the extent of damage, and the amount of knowledge were the independent variables are shown in Table 2. The symbols on the top right of the numbers indicate their statistical significance. First, the perceived extent of damage determines the perceived size of the risk. However, there may be factors that are not significant as far as their probabilities are concerned. In particular, if the probability of the hazard are low or if it is a frequently occurring hazard, then there is a possibility of a deterministic rather than probabilistic evaluation of the risk under consideration. On the other hand, none of the factors were statistically significant regarding the amount of knowledge. In addition, the adjusted coefficient of determination (the proportion of the variation in the dependent variable that can be explained by a given independent variable) is smaller for the effects of on-site fires than for the other factors.

\subsection{Relationship of Risk Perception with Benefits and Trust}

The data were summarized using factor analysis package R2.7.1. The number of factors in the factor analysis

Table 1. Age distribution of respondents (gender distribution: $101=$ male, $102=$ female, and $5=$ unknown).

\begin{tabular}{cccc}
\hline Age group & Number of respondents & Response rate (\%) \\
\hline 20 & 18 & 29.5 \\
30 & 29 & 36 & 40.3 \\
40 & 42 & 39.8 \\
50 & 39 & 43.7 \\
60 & 43 & 36.4 \\
71 and older & 1 & 208 & - \\
Unknown & & 41.6 \\
Total &
\end{tabular}


Table 2. Relationship between the perception of the extent of the risk and the amount of knowledge.

\begin{tabular}{ccccc}
\hline Type of hazard & Probability of occurrence & Extent of damage & $\begin{array}{c}\text { Amount of } \\
\text { knowledge }\end{array}$ & $\begin{array}{c}\text { Adjusted coefficient of } \\
\text { determination }\end{array}$ \\
\hline Core meltdown & 0.033 & $0.540^{* * *}$ & 0.000 & 0.337 \\
Radiation leakage & $0.079^{+}$ & $0.502^{* * *}$ & -0.018 & 0.350 \\
$\begin{array}{c}\text { Radioactive water release } \\
\text { Failure of machinery and } \\
\text { piping }\end{array}$ & $0.110^{* *}$ & $0.494^{* * *}$ & 0.004 & 0.356 \\
Fire at the site & 0.020 & $0.573^{* * *}$ & 0.019 & 0.344 \\
\hline
\end{tabular}

${ }^{*}=\mathrm{p}<0.05,{ }^{* *}=\mathrm{p}<0.01,{ }^{* * *}=\mathrm{p}<0.001$.

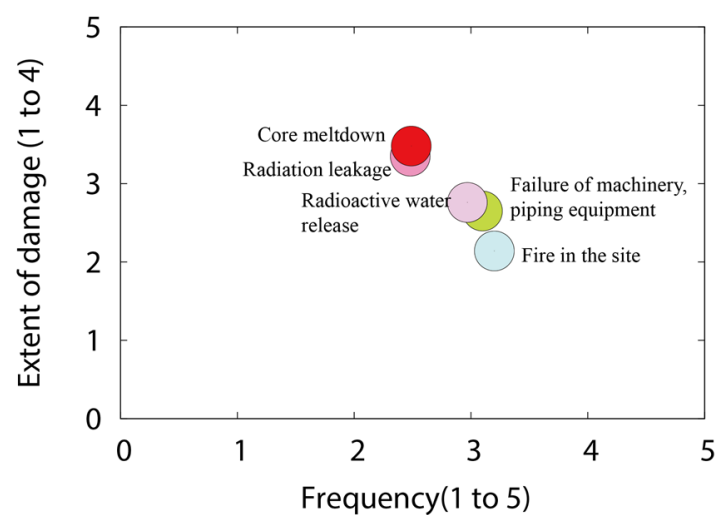

Figure 1. Respondents' risk perceptions (sizes of the circles indicate the extent of unacceptability) Size of data points show the extent of severy of hazard.

was specified as three to correspond with the factors found in previous studies. Applying a varimax rotation, the factor scores were calculated using maximum likelihood estimation. The results of the analysis are shown in Table 3. Items with loadings greater than 0.4 on one factor that did not show a loading greater than 0.4 on other factors were chosen. Because the third factor consists of items that indicate benefits to the nuclear energy industry, it was termed the "social benefit" factor. Because the second factor consists of items that result in benefits to the local community, it was termed the "regional interests" factor. Because the first factor consists of items that express the respondents' trust in the safe running of the nuclear power plant, it was termed the "trust in the company" factor. The value of the coefficient $\alpha$ indicating the internal consistency of the items that comprise afactor was close to 0.8 for all of the factors, which is considered a sufficient value. This composition of items is identical with that of Kimura (2003). Thus, since a factor for determining the acceptability of risk often comprises the risk as well as the benefits of and the confidence in the business entity, this study's composition factor for benefits and trust are appropriate. The arithmetic mean of the configured items was used as the factor score of the subordinate factors.

The combined impacts of the factors of "social benefits," "regional interests," and "trust in the company," and the amount of knowledge on the extent of unacceptability of the risk, were assessed with a multiple regression analysis. The results are shown in Table 4. The negative coefficients indicate that the extent of acceptability increases due to the influence of that factor. The measures of social benefits and trust in the company were statistically significant, whereas regional interests that might be expected to have direct advantages were not statisticily significant. Moreover, the amount of knowledge was not statistically significant for any of the items. Although an increase in knowledge tends to positively relate to trust in people with values that are similar to one's own, no such correlation was found in this study. A detailed study of the item of improvement of the amount of knowledge is necessary.

\subsection{Awareness of the Values of the Company}

Five questions were asked to learn about the benefits and the extents of commonality between the company and 
Table 3. Factor analysis results of items related to benefits and trust.

\begin{tabular}{|c|c|c|c|}
\hline Question & $\begin{array}{l}\text { Factor } 1 \\
(\alpha=0.908)\end{array}$ & $\begin{array}{l}\text { Factor } 2 \\
(\alpha=0.842)\end{array}$ & $\begin{array}{c}\text { Factor } 3 \\
(\alpha=0.791)\end{array}$ \\
\hline A1: I think a nuclear power plant is necessary for stable power supply & 0.267 & 0.226 & 0.642 \\
\hline $\begin{array}{l}\text { A2: I think the use of nuclear power plants is an effective countermeasure } \\
\text { against global warming }\end{array}$ & 0.171 & 0.158 & 0.864 \\
\hline $\begin{array}{l}\text { A3: I think a nuclear power will be able to provide relatively inexpensive } \\
\text { electricity }\end{array}$ & 0.237 & 0.357 & 0.508 \\
\hline $\begin{array}{l}\text { A4: I think a nuclear power plant will increase employment opportunities in } \\
\text { the region }\end{array}$ & 0.218 & 0.727 & 0.218 \\
\hline A5: I think a nuclear power plant will enhance local facilities & 0.238 & 0.765 & 0.29 \\
\hline $\begin{array}{l}\text { A6: I think a nuclear power plant will make the population in the region } \\
\text { increase }\end{array}$ & 0.163 & 0.748 & 0.116 \\
\hline B2: I think the workers in nuclear power plants are well trained & 0.688 & 0.252 & 0.1 \\
\hline $\begin{array}{l}\text { B3: I think the problems that can occur in a nuclear power plant are well } \\
\text { anticipated and suitable measures are being taken }\end{array}$ & 0.781 & 0.232 & 0.139 \\
\hline $\begin{array}{l}\text { B4: I think the emergency response system in the event of a disaster or } \\
\text { accident in nuclear power plants has been well established }\end{array}$ & 0.805 & 0.208 & 0.216 \\
\hline $\begin{array}{l}\text { B5: I think the record of operations and inspection in nuclear power plants is } \\
\text { well maintained }\end{array}$ & 0.784 & 0.107 & 0.184 \\
\hline $\begin{array}{l}\text { B6: I think that problems that occur within nuclear power plants are recorded } \\
\text { properly and official announcements are made to the outside world }\end{array}$ & 0.79 & 0.19 & 0.273 \\
\hline $\begin{array}{l}\text { B7: I think the authorities in nuclear power plants learn from problems that } \\
\text { occurred in other places and take preventive measures }\end{array}$ & 0.769 & 0.141 & 0.214 \\
\hline Factor contribution extent & 3.851 & 2.102 & 1.792 \\
\hline Factor contribution ratio & 0.321 & 0.175 & 0.149 \\
\hline Cumulative contribution ratio & 0.321 & 0.496 & 0.645 \\
\hline
\end{tabular}

Table 4. Relationship of the extent of risk with benefits and trust.

\begin{tabular}{ccccc}
\hline Variable & Social benefits & $\begin{array}{c}\text { Regional } \\
\text { interests }\end{array}$ & $\begin{array}{c}\text { Trust in the } \\
\text { company }\end{array}$ & $\begin{array}{c}\text { Amount of } \\
\text { knowledge }\end{array}$ \\
\hline $\begin{array}{c}\text { Magnitude of risk } \\
\text { (unacceptability) }\end{array}$ & $-0.162^{* * *}$ & -0.004 & $-0.200^{* * *}$ & 0.014 \\
\hline
\end{tabular}

${ }^{*}=\mathrm{p}<0.05,{ }^{* *}=\mathrm{p}<0.01,{ }^{* * *}=\mathrm{p}<0.001$.

the respondents regarding values related to trust. For each question, respondents chose one of five options, where 1 = I think so through $5=$ I do not to think so. The questions were: 1 ) Do you think the company must be trusted by the local community? 2) Do you think the company must not cause accidents? 3) Do you think the company must not cause radiation leakage? 4) Do you think the company must strive to provide a stable power supply? 5) Do you think the company must contribute to the community? The average of the responses to the five questions was greater than four points in the five-point scale and the standard deviation plus the mean exceeded the highest point, suggesting a ceiling effect. In other words, the respondents demonstrated a substantially uniform response to these questions. Although there was a lack of clarity regarding the respondents' opinions, such as, "I believe the company should be thinking in such and such a manner" or, "I am aware that the company should be doing such and such things," the positive responses obtained were unexpectedly high.

\subsection{Awareness of Engineers' Requirements}

There were 16 questions about factors that the respondents thought were necessary to enable engineers to understand the advantages and disadvantages of nuclear power plants. The questions consisted of four categories: 1) proficiency in nuclear energy and safety, 2) regional affinity of engineers, 3) communication skills, and 4) sense of belonging to the organization. Among these responses, a ceiling effect was observed with respect to profi- 
ciency in nuclear energy and safety and communication skills, just as was found in the case of awareness of the values of the company. This finding shows that the respondents had a nearly uniform response with respect to these items. In other words, because it is a matter of course that an engineer involved in risk communication is equipped with relevant knowledge about nuclear power and safety, it is expected that his or her communication skills are naturally high.

Regarding items such as regional affinity and commitment to the organization, there were no statistically significant correlations with the other items. This finding does not necessarily mean that these items have no relevance to public acceptance of nuclear power plants. Whereas the first set of questions concerned nuclear power plants and a specific company, this set of questions concerned general technical personnel. Thus, direct relevance to the respondents may not have been recognized. In any case, a more detailed investigation is necessary.

\subsection{Regarding the Requirements of Engineers Involved in Risk Communication}

It can clearly be seen from the risk perception map shown in Figure 1 that the respondents had very rational perceptions of risk. In particular, the fact that they clearly distinguished between the extent of risk due to radiation and other kinds of risks is evidence of their anxiety about the damage caused by radiation, given their position as local residents. The probability (frequency) of an occurrence evidently did not have much of an impact on them. This result leads us to believe that if knowledge of the inherent risks in a power plant and the relevant measures that are being taken under the assumption of their occurrence (deterministically) were shared with local residents in a rational manner, then local residents' acceptance of the risk would increase.

On the other hand, although the risks due to factors other than radiation were not given much importance, we cannot conclude that measures against them are regarded as unnecessary. If the local public believes that measures for prevention and recurrence are not in place, their trust may be undermined, resulting in the risk becoming unacceptable to the public. In this sense, it is necessary to reveal to the public the fact that reasonable measures for prevention and recurrence have been taken, even regarding risks that are unrelated to radiation.

Because the extent of the risk was negatively correlated with the factors relating to social benefits of nuclear power and trust in the company, it is important to vigorously communicate the fact that trust and nuclear power plants have social benefits and that the nuclear power plant in Kashiwazaki, in particular, is useful for all of Japan. The greater the acknowledgement of social benefits, the more the acceptance of the risk of nuclear power plants may be expected to grow. As a prerequisite for this, it is essential that the activities of the power plant gain the trust of the local people. The responses in this survey indicate that it is necessary for the company to obtain the people's trust and, although efforts are being made and awareness is being created, continued efforts are needed. Regarding the answers to the questions on regional interests, Kimura et al. observed that a factor of risk tolerance is weakly correlated with the regional interests factor [6]. It is necessary to carefully examine whether this tendency is related to the respondents' characteristics.

The qualifications of engineers who are involved in risk communication need to be studied in detail. However, as was learned from the extent of awareness of the local residents, expert knowledge in nuclear power, communication skills, and expertise regarding safety are minimum desirable qualities. Furthermore, the relationship between engineers' regional affinity and their sense of belonging to their organization needs to be examined. Fukushima NPP disaster affected risk perception of not only in Japanese people, but also in Chinese or another international people [8]. Continuous observations on risk perception of residents are important to reveals the effectiveness of risk communications by engineers.

\section{Conclusions}

This study observed the relationship among risk assessment, risk perception model and risk perception model of local residents near NPP in Kashiwazaki-Kariwa region. The summary of the results is as follows.

1) The extent of the severity of risk is significantly affected by the perceived extent of damage due to a given hazard. In particular, radiation-related hazards are perceived as more severe than other hazards.

2) The extent of acceptance on the risks by NPPs is significantly related to the factors of social benefits by NPP and trust to NPP Company by the local residents. The benefits to the local region are not found to be statistically significant on risk acceptance model.

3) Respondents' amount of knowledge is not significantly correlated with any of the items. The results sug- 
gest that only technical explanation to the resident is not sufficient to establish mutual reliable relationship between NPPs engineers and local residents.

4) Value similarity between NPPs with local residents is not statistically significant. Nuclear power plants company is perceived as making efforts to gain public trust in the region.

5) NPP engineers are expected to possess expert knowledge in nuclear power, communication skills and expertise in safety in order to conduct more smooth risk communication.

The result demonstrates that risk acceptance model of local residents to NPPs can be arranged by traditional trust model. The result by this study is beneficial for risk communicators to manage communication framework with local residents.

\section{Acknowledgements}

This study was partly supported by a jointly funded research project of "regional contribution function" of the University by Niigata prefecture in 2009. The author greatly appreciates anonymous residents of Kashiwazaki, Niigata, and Kariwa for their cooperation in participating in this study.

\section{References}

[1] IAEA (1996) Defense in Depth in Nuclear SSAFETY (INSAG-10). IAEA, Vienna.

[2] Slovic, P. (2000) The Perception of Risk. Earthscan Publishing Ltd., London.

[3] Morgan, M.G., Fischhoff, B., Bostrom, A. and Cynthia J. Atman, C.J. (2001) Risk communication. Cambridge University Press, Cambridge. http://dx.doi.org/10.1017/CBO9780511814679

[4] Nakayachi, K. and Cvetkovich, G. (2008) Trust of Risk Managers: An Integration of the SVS Model and the Traditional View of Trust. The Japanese Journal of Social Psychology, 23, 259-268.

[5] ISO 14120:2002 (2002) Safety of Machinery—Guards—General Requirements for the Design and Construction of Fixed and Movable Guards.

[6] Kimura, H., Furuta, K. and Suzuki, A. (2003) Psychological Factors Affecting Public Acceptance of Nuclear Energy: Comparative Analysis Focusing on Regional Characteristics and Degree of Knowledge Prasad. Transactions of the Atomic Energy Society of Japan, 2, 379-388.

[7] Yagi, E., Takahashi,S. and Kitamura, M. (2007) Clarification of Nuclear Risk Recognition Scheme through Dialogue Forum. Transactions of the Atomic Energy Society of Japan, 6, 126-140.

[8] Huang, L., Zhou, Y., Han, Y.T., Hammitt, J.K., Bi, J. and Liu, Y. (2013) Effect of the Fukushima Nuclear Accident on the Risk Perception of Residents near a Nuclear Power Plant in China. Proceedings of the National Academy of Sciences of the United States of America, 110, 19742-19747. http://dx.doi.org/10.1073/pnas.1313825110 